medicine and, by implication, the problems that remain unresolved when treated conventionally.

We thank Dr Julian Kenyon for allowing us to interview his patients, all the patients who attended the centre, and Mrs J Burnham for her help with the manuscript.

1 Fulder S, Munro R. The status of complementary medicine in the UK. London: Threshold Foundation, 1982 .

2 Taylor-Reilly D. Young doctors' views on alternative medicine. $\mathrm{Br}$ Med $\mathcal{F} 1983$;

3 Snaith RP, Ahmed SN, Mehta S, Hamilton M. Assessment of the severity of primary depressive illness. Wakefield self-assessment depression inventory.

(Accepted 23 October 1984)

Southampton University

JUDITH MOORE, fourth year medical student

KATHY PHIPPS, fourth year medical student

DONALD MARCER, BSC, PHD, senior lecturer in psychology

Centre for the Study of Alternative Therapies, Southampton SO1 2DG

GEORGE LEWITH, MRCP, MRCGP, director

Correspondence to: Dr George Lewith.

\section{Is the flow rate used to drive a jet nebuliser clinically important?}

Jet nebulisers are increasingly being used to provide high dose bronchodilator treatment, both in hospital and at home. The flow rate of the driving gas through a nebuliser directly affects the size of the particles generated, and for most nebulisers flow rates of less than $6 \mathrm{l} / \mathrm{min}$ produce droplets with a mass median diameter that is considered to be too large for tracheobronchial deposition. ${ }^{1}$ This could imply that at lower flow rates the response to a bronchodilator aerosol would be diminished, even if the same dose of the drug is inhaled. We tested this hypothesis by comparing the bronchodilator response to rimiterol nebulised at $41 / \mathrm{min}$ and $81 / \mathrm{min}$ in a group of patients with chronic stable asthma.

\section{Patients, methods, and results}

Eight patients with chronic stable asthma took part in two cumulative dose response studies on consecutive mornings using nebulised rimiterol driven by oxygen at 4 and $8 \mathrm{l} / \mathrm{min}$. Each patient had reversible airways' obstruction with an improvement of at least $20 \%$ in response to bronchodilators and had an initial forced expiratory volume in one second of $33-76 \%$ of the predicted normal value. Rimiterol was chosen because of its

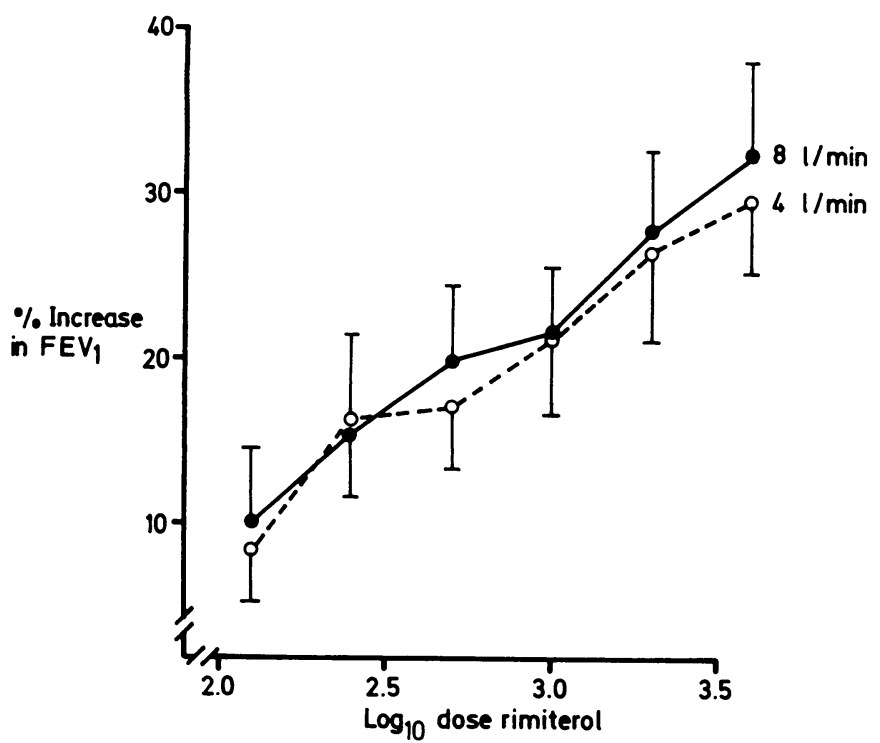

Log dose response curves for percentage increases in forced expiratory volume in one second $\left(\mathrm{FEV}_{1}\right)$ after inhalation of nebulised rimiterol. Bars represent SEM. lack of gastrointestinal absorption, ${ }^{2}$ which might have augmented the inhaled bronchodilator response. The forced expiratory volume in one second and the forced vital capacity before treatment were within $10 \%$ on the two study days. We had previously found that, of a $5 \mathrm{ml}$ solution placed in an Inspiron Mini-Neb nebuliser, $2 \mathrm{ml}$ was nebulised in six minutes at a flow rate of $41 / \mathrm{min}$ and $3.7 \mathrm{ml}$ in six minutes at $81 / \mathrm{min}$. Taking this into account we prepared dilutions of rimiterol for nebulisation to provide six doses in $5 \mathrm{ml}$ for the two flow rates, starting with $125 \mu \mathrm{g}$ and increasing by doubling dilutions to a cumulative dose of $7.9 \mathrm{mg}$. The duration of inhalation for each dose and flow rate was six minutes. The forced expiratory volume in one second, forced vital capacity, and pulse rate were measured immediately before and 15 minutes after each nebulisation. The next incremental dose was then given. The percentage changes in forced expiratory volume in one second, forced vital capacity, and pulse rate were plotted against the log cumulative dose of rimiterol to produce log dose response curves for each flow rate. Wilcoxon's rank sum test was used to compare the bronchodilator responses.

The figure shows the log dose response curves for the mean percentage increases in forced expiratory volume in one second at each flow rate. There were no significant differences between the mean percentage increases in forced expiratory volume in one second and forced vital capacity, and between the mean changes in pulse rate, with any dose of rimiterol at either flow rate, the dose response curves being similar and not separated.

\section{Comment}

The ideal diameter of particles for a $\beta$ adrenergic bronchodilator aerosol is probably $2-5 \mu \mathrm{m} .{ }^{3}$ When the flow rate is increased from 4 to $8 \mathrm{l} / \mathrm{min}$ the median diameter of the droplets generated by most nebulisers is reduced, which results in an increase in the percentage of the aerosol within the "optimum" respirable range. ${ }^{1}$ Although an Inspiron Mini-Neb nebuliser generates an aerosol with a median particle diameter of $4 \mu \mathrm{m}$ at $81 / \mathrm{min}$ and $11 \mu \mathrm{m}$ at $41 / \mathrm{min},{ }^{1}$ these flow rates in our study produced similar increases in forced expiratory volume in one second and forced vital capacity. This suggests that in patients with chronic stable asthma the clinical response to a nebulised bronchodilator does not diminish when the flow rate of the driving gas is reduced from 8 to $4 \mathrm{l} / \mathrm{min}$. Thus the difference in distribution of particle sizes produced by a jet nebuliser at these two flow rates may not be critically important to the bronchodilator response.

Even at the "high" flow rate $(4 \mathrm{l} / \mathrm{min})$, a standard National Health Service oxygen cylinder driving a nebuliser such as the Inspiron Mini$\mathrm{Neb}$ generates a distribution of particle sizes that are theoretically too large for tracheobronchial deposition. ${ }^{1}$ Our study suggests, however, that this readily available method of delivering a bronchodilator aerosol is clinically effective.

1 Clay MM, Pavia D, Newman SP, Clarke SW. Factors influencing the size distribution of aerosols from jet nebulisers. Thorax $1983 ; 38: 755-9$

2 Evans ME, Shenfield GM, Thomas N, Walker SR, Paterson JW. The pharmacokinetics of rimiterol in man. Xenobiotica 1974;4:681-92. kinetics of rimiterol in man. Xenobiotica $1974 ; 4: 681-92$.
Rees BJ, Clark TJH. The importance of particle size in response to inhaled
bronchodilators. Eur f Respir Dis 1982;63(suppl 119):73-8.

(Accepted 12 October 1984)

Respiratory Medicine Service, Northern General Hospital, Edinburgh EH5 2DQ

J GRAHAM DOUGLAS, MRCP, senior registrar

MOIRA J LESLIE, BSC, scientist

GRAHAM K CROMPTON, FRCP, consultant

IAN W B GRANT, FRCP, consultant

Correspondence to: Dr J G Douglas.

\section{Shredding of manuscripts}

From 1 January 1985 articles submitted for publication will not be returned. Authors whose papers are rejected will be advised of the decision, and the manuscripts will be kept under security for three months, to deal with any inquiries, and then destroyed by shredding. Hence we would prefer to receive for consideration photostats or copies produced by word processor (see $B M \mathcal{F} 13$ October, $\mathrm{p} 942$ ), though we do, of course, still need three copies. 